\title{
Measuring and Tracking Externalized Work to Support Industrialized Construction
}

\author{
Dr. Perry DANESHGARI ${ }^{1}$, Dr. Heather MOORE ${ }^{2}$ and Dr. Hisham SAID ${ }^{3 *}$ \\ ${ }^{1}$ President \& CEO, MCA, Inc.; Professor, University of Michigan-Dearborn \\ ${ }^{2}$ Vice President of Operations, MCA, Inc. \\ ${ }^{3}$ Assistant Professor, Santa Clara University \\ *Corresponding author's e-mail: hsaid@scu.edu
}

\begin{abstract}
The same principles that have made other skilled-trade-based industries more efficient are being deployed in construction through Industrialization, which requires understanding skilled trade work and segregating/externalizing the work from the jobsite. The construction industry still relies heavily on skilled trades and their tacit knowledge, while most of the information available at the points of installation is not passed on. A significant increase of work externalization requires a measuring and tracking method that can: 1) tap into this tacit knowledge as the basis for work planning and control; and 2) understand, quantify, and minimize the manipulation effort done onsite for the prefabricated assemblies. As such, this paper presents a planning and control framework for industrialized construction operations that integrates information entropy and the novel concept of work manipulations to monitor and measure the expected performance outcomes, in a more sophisticated approach beyond measuring "hours" and "quantities" of the work. The development of the proposed framework is based on the analysis of a set of case studies that illustrate the impact of information predictability manipulation strategies on construction prefabrication decisions.
\end{abstract}

\section{KEYWORDS}

Industrialized construction, prefabrication, tracking, work manipulation, information entropy.

\section{INTRODUCTION}

Over the past four decades, while productivity has improved by more than four-fold in all industries, construction productivity has declined or in best case, has remained stagnant, (Daneshgari and Moore, 2015(a)). Despite research to improve products and tools used for building, the processes for managing projects in construction have not evolved as mainstream, which increases the cost for end users. Over the past ten years, signals of Industrialization have appeared, primarily from Europe and Asia, with fast-paced and low-cost alternatives to the way North American construction still operates as a whole. With recent construction industrialization efforts, the construction industry can expect to follow suit of other skilled-trade-based industries that have industrialized. Industrialization happens through five steps: 1) Management of Labour; 
2) Management of Work; 3) Lean Operations; 4) Modelling and Simulation; and 5) Feedback from the Source (Daneshgari and Moore, 2015(a)).

Construction still relies heavily on skilled trade's knowledge for work and integration of work. This knowledge and experience needs to go from tacit to explicit states with steps 1 and 2 of industrialization, before it can be optimized and improved with lean techniques and modelling. As the trade knowledge is made explicit, options for doing and integrating work differently will be possible, including significant increases in how much can be work can be externalized. The current approaches to prefabrication are ad hoc, rigid, and very simple compared to what is feasible in construction. To ramp up the amount of prefabrication that is possible both within and between trades, the process of Work Breakdown Structure (WBS) for transferring trade knowledge from tacit to explicit is required (Daneshgari and Moore, 2015(a); Daneshgari and Moore, 2014(b)). Once this process is mainstream, a new approach for managing and tracking agile prefabrication will be needed, as opposed to today's simplified approaches to measuring.

Limited research investigated the role of tacit knowledge industrialized construction, such as the study done by Sandberg et al. (2008) for knowledge-based configuration of prefabricated timber homes design. In addition, project control and tracking models were previously developed without differentiating offsite and onsite work in industrialized construction, which included the utilization of Delphi method (Gharaibeh 2014), stochastic control tools (Barraza and Bueno 2007), earned value analysis (Kim 2004, Turkan et al. 2013). In the context of industrialized construction, the previous limited research (Azimi et al. 2012) ignored the relation between offsite operations and the onsite production and installation activities based on the trades' knowledge of all the work through final assembly and customer acceptance. The ASTM E2691, Standard Practice for Job Productivity Measurement, was developed to account for the full usage of Work Breakdown Structure and an overarching codification structure such as UNIFORMAT II that can be used across projects and types of work. However, the method has not yet been explored and used for the previously-mentioned digital approach for tracking prefabrication (ASTM E2691-15, Daneshgari and Moore, 2014(b)).

\section{NEED FOR A NEW TRACKING APPROACH}

Current tracking approaches to prefabrication fall short in two ways: (1) they are missing the basis of using work to identify, codify, and quantify prefabrication, and (2) they will not be scalable with the pace of industrialization and the amount of work externalization.

Prefabrication has evolved in construction over the past decades, with more and more assemblies being built away from the jobsite, and shipped for installation. However, the suggestions for externalized work are coming from subcontractors only $20.9 \%$ of the time, who are the true source of the work technical knowledge (NIBS 2014). This means that there is significantly more prefabrication that can be done as the work is made visible. Subcontractors still experience barriers to doing more prefabrication, some of which tie back to the way the benefits are perceived and measured. Even if they can identify the benefits, very few contractors have been able to successfully quantify the benefits. Those contractors who try to quantify prefab very often use an approach of comparing hours or labour spent on prefab vs. traditional non-prefab approaches. A new approach is needed to quantify the work first, based on the explicit knowledge of the work, which will be explained in the next section. 
As construction goes through Industrialization, the requirements for information management will become more complex. Onsite production will become a minor component of the entire work on a project, and a more rigorous method will be needed to measure work at a much finer level of precision than is done today. Dr. Shewhart developed the Statistical Process Control method to accomplish the same outcome when industrialization hit the manufacturing industry (Shewhart 1931). Construction requires new control approaches to integrate the monitoring of onsite and externalized offsite work (Azimi et al. 2012). Also, traditional industrial tracking approaches are only scalable for standardized products that are fabricated in mass production settings. As such, these traditional tracking approaches lack the flexibility required to manage agile construction operations that respond to varying design requirements and site conditions.

This paper presents the development of a planning and control framework for industrialized construction operations that integrates information entropy and work manipulations to measure operational performance outcomes. The proposed framework utilizes new metrics to facilitate the simultaneous consideration of onsite and externalized offsite work, which are materialized by knowledge transfer from tacit to explicit state. The following sections present the development of the proposed framework by: 1) reviewing the nature of tacit knowledge and its transfer to explicit knowledge; 2) reporting 4 case studies that illustrate the role of manipulation, information predictability in planning construction prefabrication work; and 3) explain the framework methodology through its potential application in planning and tracking the prefabrication of electrical assemblies. The paper concludes with a summary of the possible outcome and benefits of the framework and future research work.

\section{TRANSFERRING TRADE KNOWLEDGE FROM TACIT TO EXPLICIT}

Tacit knowledge is knowledge that is "tribal" or known only through informal channels, and most often stored in individuals' memory banks. Explicit knowledge, on the other hand, is knowledge that is made visible and can be accessed beyond any one person. According to Polanyi, M, (1962), tacit knowledge can be categorized to three major areas:

- Codifiability and mechanism of transferring knowledge: the explicit knowledge can be codified to cost codes and activities, and easily transferred without the knowing subject, where the tacit knowledge is intuitive and unarticulated that cannot be communicated, understood or used without the 'knowing subject', such as layout and visualization of the job.

- Main methods for the acquisition and accumulation: Explicit knowledge can be taught through formal classes and training programs, where in contrast, tacit knowledge can only be acquired through practical experience and trade training.

- Potential of aggregation and modes of appropriation: Explicit knowledge can be aggregated under a cost code or a system, stored in objective forms and appropriated without the participation of the actual person doing it. Tacit knowledge in contrast, is personal contextual. It is distributive, and cannot easily be aggregated.

The process of transforming tacit knowledge into explicit or specifiable knowledge is known as codification, articulation, or specification. In construction and project-based environments Work Breakdown Structure (WBS) does the codification, articulation and specification (Daneshgari and Moore, 2016). WBS is a creative and thought-provoking approach to planning work that is done by having the holder of the tacit knowledge (tradesman) to identify the work required to complete the overall project, broken down by phases, systems, activities, tasks, etc. Once the work is identified, it can be explored for opportunities to be done outside of the jobsite space and 
time. Figure 1 shows a schematic of this as the dimensions of a work cube which can be planned, measured, and tracked with a common approach that ties everything back to the work identified in each cubelet (Daneshgari and Moore, 2015(a)).

The means and methods that the skilled trade labour uses for their work are based on their tacit knowledge and preference for manipulating materials and assemblies to "make it fit." The number of manipulations for any given work activity or assembly can be in the hundreds, due to the options of the material, the jobsite environment, and personal experience or knowledge of the skilled trade. To fully comprehend the options available for what can be externalized, and how to measure it, the level of manipulations that are possible need to be identified.

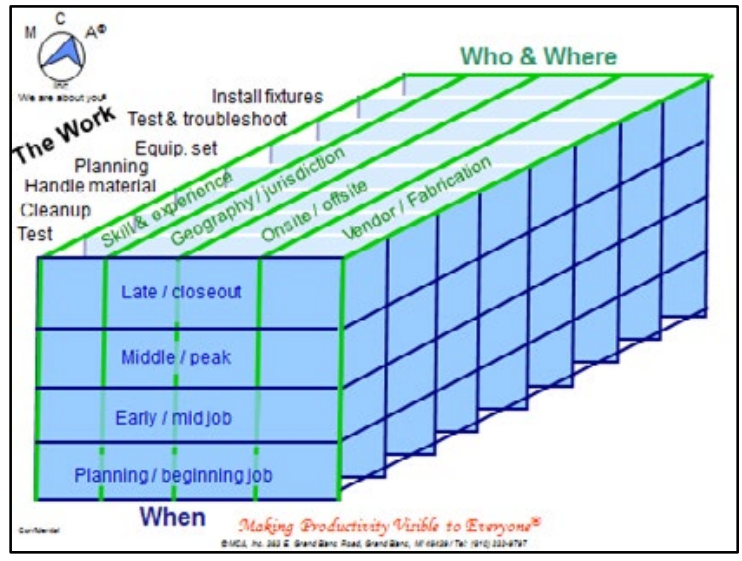

Figure 1. The Work Breakdown Cube

\section{CASE STUDIES OF PREFABRICATION MANIPULATIONS}

Manipulations to prefabricated assemblies can be performed to account for varying site conditions and compatibility between the different building systems and trades. Onsite manipulations, which increase variation and lead to higher requirements of explicit knowledge can be minimized by streamlining prefabricated assemblies design, offsite fabrication, and onsite installation. However, different physical and informational factors can drive the need to allow onsite manipulations, which are investigated using the following 3 case studies.

\section{Case 1 - Prefab Rebar Cages for Walls}

The first case study entails the fabrication and installation of rebar cages for exterior building structural concrete walls. The structural engineer produced a standardized design for the panels to facilitate panelization with less design variations between the panels. However, the engineer decided to assemble the rebar cages with no opening in the fabrication shop and left to be cut in the jobsite, which increased the manipulation required onsite. This increased level of site manipulation was permitted to: 1) increase the stiffness of such heavy rebar cages to avoid damage during transportation; and 2) decrease the tolerance levels required the formwork cutting and trimming of the window openings.

\section{Case 2 - Prefab Rebar Cages for Beams}

In traditional rebar detailing, beam reinforcement bars are cut to lengths that extended inside the columns. However, this detailing requirement is hard to respect when trying to lay prefabricated rebar cages inside the formwork while inserting the rebar cages through the columns over adjacent spans, which results in high onsite manipulation effort. Accordingly, the structural engineer utilized a new detailing where beam rebar cages are cut to lengths that just extend to the edges of the columns, with additional reinforcement bars that go through the columns and extend inside the adjacent beam cages. This new detailing reduced manipulation levels, but results in additional material weight and cost. 


\section{Case 3 - Building Electrical Products}

Manufacturers of electrical products actively seek feedback from electrical contractors to increase the flexibility of their products and improve the agility of construction operations. New electrical outlet boxes were made available with adjustable mud rings that can be screwed in or out to modify its surface to the wall finish. In addition, mounting brackets between studs can also be offered with a telescopic adjustable length that can be set to accommodating different spacing between the studs. These two product examples illustrate a case where contractors collaborate with manufacturers to design products that can embrace site manipulations to easily accommodate the unavailability of interface information between trades.

\section{MANIPULATION STRATEGIES}

Based on the previous case studies and the previous experience of the authors, strategies to control and minimize onsite manipulations can be grouped in 4 categories:

1) Avoidance: actions are taken to avoid the sources of increased manipulation work, such as the avoidance of extending the beam rebar cages inside the columns (the $2^{\text {nd }}$ case study).

2) Flexibility: assemblies and products are designed with flexible configurations to reduce manipulation effort, such the recent designs of electrical assemblies (the $3^{\text {rd }}$ case study).

3) Redundancy: redundant material and parts are allowed in the assemblies to be manipulated onsite due to the unavailability of sufficient information to perform work offsite with no onsite manipulations. The $1^{\text {st }}$ case study (wall rebar cages) is an example of this strategy.

4) Standardization: standard libraries are used for prefabricated assemblies and made available to site crews, as a way to make design and installation information more predictable, which results in less onsite manipulations.

\section{MANIPULATION-BASED TRACKING FRAMEWORK FOR INDUSTRIALZED CONSTRUCTION EXTERNALIZED WORK}

A four-step framework is proposed to measure, track, and control industrialized construction operations with agile plans of onsite and externalized offsite work. The framework involves feedback channels between the steps to update the decoded tacit knowledge in the form of generic work breakdown structures and cost codes, as explain next.

\section{1) Develop/Update Generic WBS using Organizational Tacit Knowledge}

A work breakdown structure is created for each project of the company using the available collective organizational tacit knowledge. Accordingly, the top levels of the generic WBS hierarchy represent the breakdown of the project into its assemblies and sub-assemblies, while the lower levels refer to the breakdown of the work tasks under each assembly. Figure 2 depicts part of an example generic WBS of electrical assemblies, which shows only the feeders (top level) and their possible work tasks. A unique modification to traditional WBS in this research is the addition of information links between the assemblies and other assemblies or trade systems. These information links represent the dependency of the assembly tasks and planning on the availability of information from other components of the same system or other trades. For example, the feeders in Figure 2 depend on the information of the partitions and Mechanical/plumping (M\&P) systems. Possible outcomes can be modelled for each link to represent the possible states of information availability, as shown in Figure 2. One possible outcome refers to the availability of $100 \%$ of all required information, which refers to the case where all work can be performed offsite without the fear of facing any onsite manipulations. The 
other extreme outcome would refer to no information is available for this specific system (e.g. partitions or M\&P), which can be better managed by having most of the work to be done onsite to avoid any unnecessary adjustment.

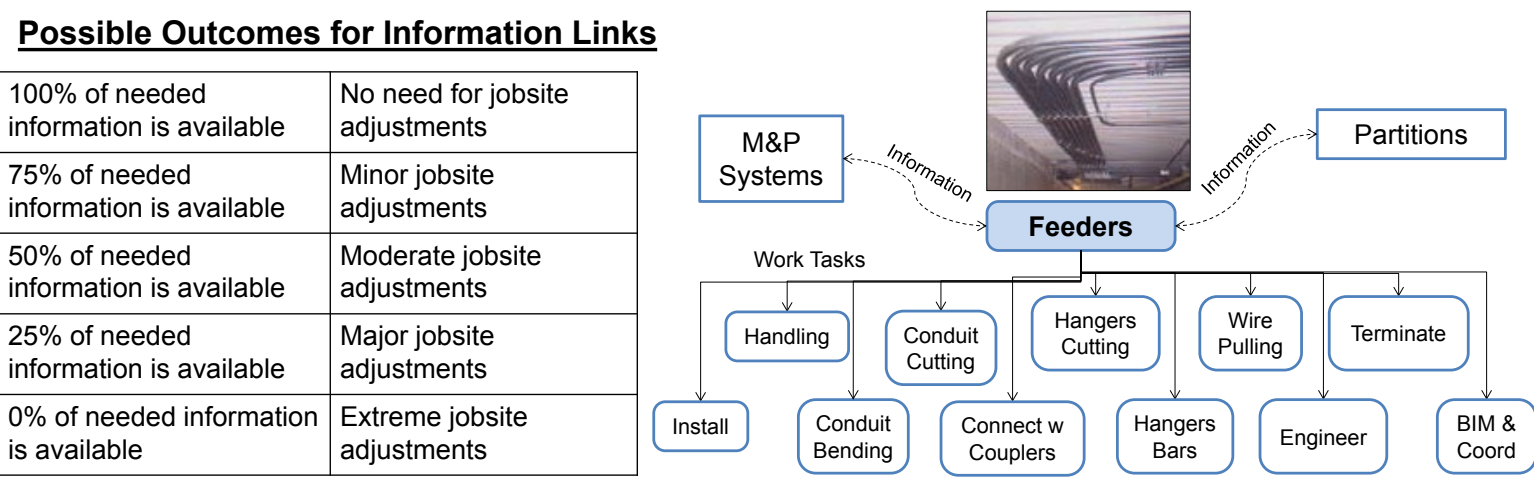

Figure 2. Work breakdown structure with information linkages

\section{2) Develop/Update Cost Codes}

The second step is to set or apply the cost coding system that will be used to track the work tasks of each assembly, over the different locations and organizations in the supply chain. In this research, cost codes apply as they do in most industrialized and other industries, for the purpose of categorizing cost types. Some contractors may also have so-called cost codes, which are really better described as labour codes or activity codes, which can also be used for further codification of the work in the WBS. The cost coding system can following the following structure: engineering (EN), building information modelling and coordination (BIM), prefabrication (PF), field installation (FI), handling and transportation (HT), vendor services (VN), manufacturer services (MF). Underneath high-level cost codes such as "FI", the applicable labour codes could include mobilization and material handling, rough-in and trim-out, for example.

\section{3) Plan Construction Operations}

The third step is to plan for the construction operation of the assembly by assigning task responsibilities and cost codes that determine the selected manipulation level. Figure 3 shows three possible planning scenarios for constructing electrical feeders, which represent varying levels of manipulation. The first scenario represents the traditional way of building these feeders by performing all labour onsite. This plan is formulated by assigning the FI cost code to all labour tasks: conduit cutting, bending, connecting with couplers, cutting the hangers, cutting the hanger bars, wire pulling, and wire termination. The other scenarios represent different levels of prefabrications, where the second scenario represents fabricating the individual feeders and the third scenario represents fabricating a whole rack of feeders. A new manipulation level (ML) metric is applied to each planned scenario as the ratio between the number of FI tasks $\left(N_{F I}\right)$ and the total number of labour tasks performed in the fabrication shop and in the field $\left(N_{F I}\right.$ and $\left.N_{P F}\right)$. As such, ML values for the first, second, and third scenarios shown in Figure 3 are 1.0, 0.75, and 0.5 , respectively. This ML metric is effective in quantifying the amount of externalized work, which is used as a parameter in measuring the resulting performance as explained in the last step.

\section{4) Monitor/Control Construction Operations}

The last step of the framework is to monitor and control the performance of the work and finished assemblies under multiple observations of manipulation levels, information 
predictability, and site conditions. Once steps 1 through 3 of the framework are repeated over multiple projects, statistical analysis can be performed on the historical data of independent and dependent variables. Dependent variables are determined by the contractors who would use the framework, which can include work hours, costs, and quality control evaluations.

Manipulation Level $\quad M L=\frac{N_{F I}}{N_{F I}+N_{P F}}$
\begin{tabular}{|c|c|c|c|}
\hline Case & $\boldsymbol{N}_{F I}$ & $\boldsymbol{N}_{P F}$ & $\boldsymbol{M L}$ \\
\hline 1 & 8 & 0 & 1 \\
\hline 2 & 6 & 2 & 0.75 \\
\hline 3 & 4 & 4 & 0.5 \\
\hline
\end{tabular}
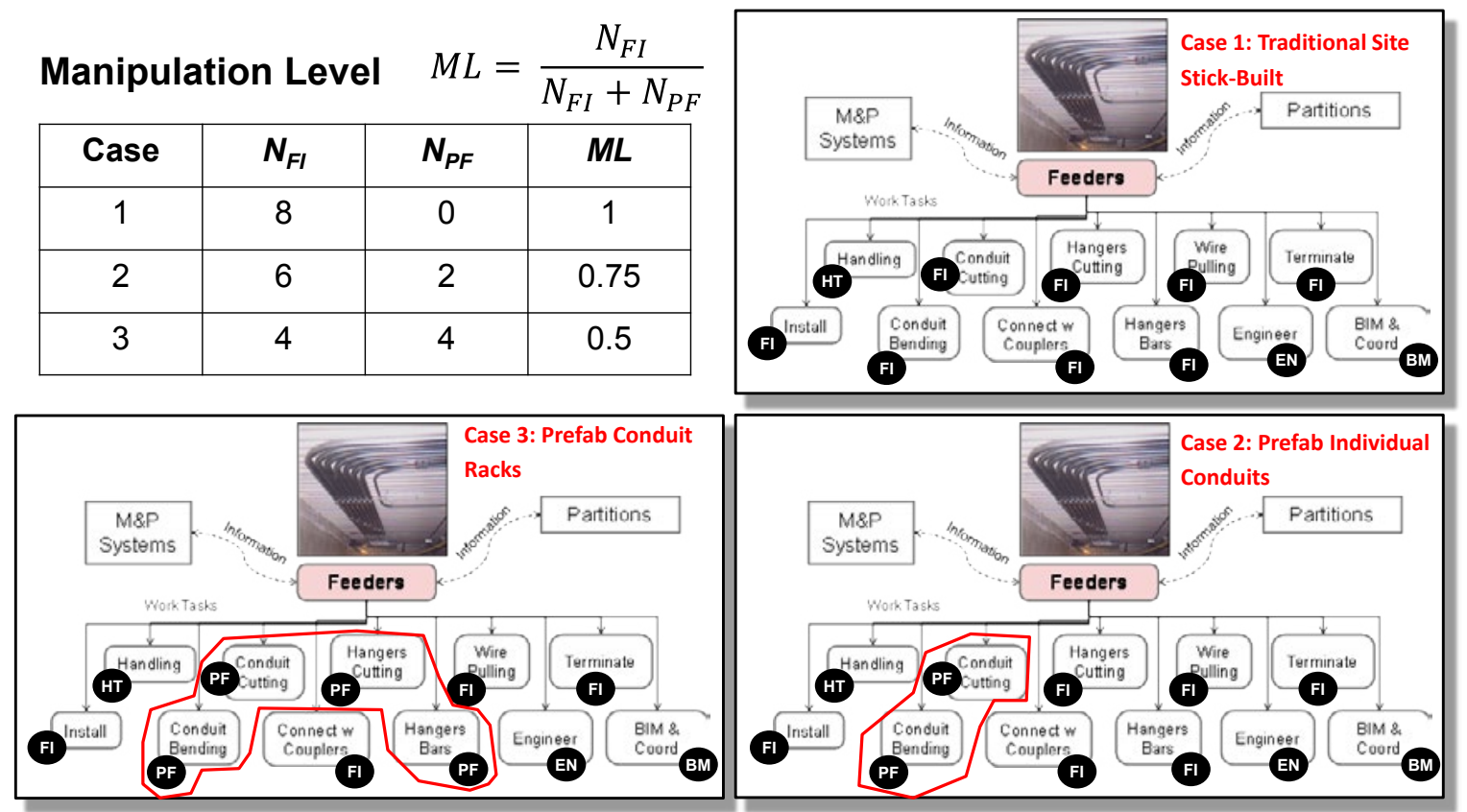

Figure 3. Manipulation level quantification for externalized construction work

Independent variables include the calculated manipulation level, information entropy, and site difficulty. First, ML value is calculated for performance observation based on the selected execution scenario of externalizing the work, as explained in the previous section. Second, the information predictability of the other trades and system that affect the assembly installation is quantified using Information Entropy $H(l)$ (Shannon, 1948) for the WBS information links $\left(l_{l}, l_{2}\right.$, ...) of the assembly, using Equation 1. For example, the third observation of building the feeders in Figure 4 has total information entropy of 1.219, which is the sum of the entropies of the assembly link with the partitions and M\&P systems. The calculation of $H(l)$ depends on the framework user to assign the probabilities of the possible outcomes on each information link. Information entropy increases with the increase of the information predictability, which can occur in both the cases of availability of unavailability of the information (i.e. minimal or maximal expected levels of site adjustments). The third and last independent variable is the site difficulty, which refers to the logistical and installation complexities for building the assembly in this observation or project.

$H\left(l_{1}, l_{2}, \ldots, L\right)=\sum_{l}^{L}\left(-\sum_{i=1}^{5} p_{i} \ln \left(p_{i}\right)\right)$

\section{EXPECTED USAGE AND OUTCOMES}

The expected outcomes of implementing the proposed framework include: 1) allowing more externalized offsite construction work to happen by identifying prefabrication opportunities and measuring their benefits/costs; 2) leading to faster prefab adoption across the industry; 3) 
improving the decision-making process about prefabrication alternatives; 4) possible adoptions as an industry standard for measurement (e.g. by ASTM); and 5) better visibility for supply chain to support prefabrication (e.g. vendors, prefab suppliers, contractors, owners).

\section{CONCLUSION}

This paper presents the formulation of a planning and control framework for industrialized construction operations that integrates information entropy and work manipulations to enable the measurements of the benefits and costs of externalizing the construction work. The framework depends on developing generic work breakdown structures using available tacit knowledge; utilizing effective cost coding structures; measuring the amount of the externalized work, and tracking its performance against experienced information predictability and observed site difficulty. Future studies are still needed to implement the framework as a computerized system and apply it in real case studies.

\section{REFERENCES}

ASTM E2691-16: Standard Practice for Job Productivity Measurement, Annual Book of ASTM Standards Volume 4-12, ASTM International, West Conshohocken, PA, 2016.

Azimi, R., Lee, S., and AbouRizk, S. (2012). "Applying Basic Control Theory Principles to Project Control: Case Study of Off-Site Construction Shops." J. Comput. Civ. Eng., 10.1061/(ASCE)CP.1943-5487.0000190, 681-690.

Barraza, G. and Bueno, R. (2007). "Probabilistic Control of Project Performance Using Control Limit Curves." J. Constr. Eng. Manage., 10.1061/(ASCE)0733-9364(2007)133:12(957), 957-965.

Daneshgari, P. and Moore, H. (2014(b)). "Feedback from the Source Improving Productivity on Construction Jobsites." Ideas to Impact: How Building Economics Standards Keep You on Track, STP 1586, Robert E. Chapman and Michael N. Goodkind, Eds., pp. 102-126, doi: 10.1520/STP158620140033, ASTM International, West Conshohocken, PA 2014.

Daneshgari, P. and Moore, H. (2015(a)). "Competing in the New Construction Environment, A Compilation to Lead the Way; Book One: The Here and Now, How to Be Competitive." ELECTRI International.

Daneshgari, P. and Moore, H. (2015(b)). "Impact of Prefabrication on Industrial Construction Work.", IEC Insight, March 2015.

Daneshgari, P. and Moore, H. (2016). "Industrialization of Construction ${ }^{\circledR}$, A Compilation to Lead the Way; Book Two: Operational Model Needed to Compete in Industrialized Construction." ELECTRI International.

Gharaibeh, H. (2014). "Cost Control in Mega Projects Using the Delphi Method." J. Manage. Eng., 10.1061/(ASCE)ME.1943-5479.0000218, 04014024.

Huang, Chapman, et al. (2009), "Metrics and Tools for Measuring Construction Productivity: Technical and Empirical Considerations", National Institute of Standards and Technology, Gaithersburg, MD, 2009.

Kim, B. (2014). "Dynamic Control Thresholds for Consistent Earned Value Analysis and Reliable Early Warning." J. Manage. Eng., 10.1061/(ASCE)ME.1943-5479.0000309, 04014077.

National Institute of Building Sciences (NIBS) (2014). Report of the Results of the 2014 Off-Site Construction Industry Survey. Prepared by the Off-Site Construction Council, Washington, DC.

Polanyi, M. (1962). Personal Knowledge: Towards a Post-critical Philosophy. Routledge and Kegan Paul Ltd, London.

Sandberg M., Jonsson H. and Larsson T. (2008). "Knowledge-based Engineering in Construction: the Prefabricated Timber Housing Case.” ITcon, 13, 408 - 420. 
Shannon D. (1948). “A mathematical theory of communication”, Bell Syst. Tech. J., (27), 379.

Shewhart, W.A. (1931). Economic Control of Quality of Manufactured Product. University of Wisconsin, Madison, WI.

Turkan, Y., Bosché, F., Haas, C., and Haas, R. (2013). "Toward Automated Earned Value Tracking Using 3D Imaging Tools." J. Constr. Eng. Manage., 10.1061/(ASCE)CO.1943-7862.0000629, 423-433. 